\title{
Oral and Maxillofacial Surgery in India: How Did We Get Here and Where Are We Going?
}

\author{
Kishore Nayak
}

\section{$1.1 \quad$ History of Our Missions and Our Challenges}

Any discussion about the history of surgery inevitably begins with an invariable reference to Suśruta and his contributions to facial surgery, in particular. While the contributions of the sixth-century sage surgeon may somewhat be nebulous in a foggy poorly documented history, they are inevitably (and arguably) numerous but need not be elaborated here in any manner. What is lesser known and not often spoken about is that Suśruta considered surgery the first and foremost branch of medicine and stated, "Surgery has the superior advantage of producing instantaneous effects by means of surgical instruments and appliances. Hence, it is the highest in value of all the medical tantras. It is eternal and a source of infinite piety, imports fame and opens the gates of Heaven to its votaries. It prolongs the duration of human existence on earth and helps men in successfully fulfilling their missions and earning a decent competence in life." $[1,2]$

When applied specifically to the context of the specialty of Oral and Maxillofacial surgery (OMS) emerging in India, it raises many important questions on how we have emerged and more importantly what we see ourselves evolving into in the years to come. Perhaps all those debates that we labored along numerous times were all a part of our coming of age!

Like elsewhere in the world, in the mid-twentieth century, we were probably practitioners of dentoalveolar surgery working under very trying circumstances moving on to where we are today. The specialty in India today, is truly all encompassing in its scope. It embraces the entire and extended spectrum of the practice of oral and maxillofacial surgery, and as the Association of Oral and Maxillofacial Surgeons of India (AOMSI) approaches its 50th year in 2019 , there is no better time to look back and reflect on the past and contemplate where we are heading. The changes

K. Nayak $(\bowtie)$

Bhagwan Mahaveer Jain Hospital, Bangalore, India that we have witnessed have been rapid and hopefully progressive. From being oral surgeons, we transitioned and added maxillofacial surgery and to our quiver and perhaps to the chagrin competing specialties treaded into areas, once considered "gray" and broadened the scope of our practices.

Mino S Ginwalla is regarded as the pioneer of oral and maxillofacial surgery in India. In the 1950s, Dr. Ginwalla arrived in Mumbai following surgical training in Montreal, Canada, and set up his practice at Nair Hospital. He was a part of the founding group of surgeons of the AOMSI in 1969. By the mid-70s, training programs were established in most of the major dental colleges throughout India. Today, there are numerous OMS training programs in India.

The dental qualified persons are governed by the statutes of the Dental Council of India [3]. Currently, the Dental Council of India provides for a comprehensive 3-year program that includes a syllabus and curriculum that exposes trainees to standard procedures covering the full spectrum of oral and maxillofacial surgery [4]. This provides a legal framework for the OMS to function. This qualification itself is only permission to practice the specialty. In today's system, competence and eventual ownership of key surgical domains often only come from structured post-qualification training.

Thus, traditionally, the specialty in India continues to be predominately a dental subspecialty that leans toward the idea of a surgical branch of dentistry. While many arguments have been made for and against the need for a medical degree to augment the specialty, it is safe to postulate that for the near future, we will remain a dental specialty for a variety of reasons. North Americans seem to have found a middle ground and of the 101 OMS training programs in the US, 55 are single-degree programs (dental degree only) and 43 are dual-degree (dental and medical) programs, and three offer both options.

Drawing comparisons to the international scenario, the specialty has always been on a pendulous path remaining undecided on the idea of whether it wants to stay a dental 
specialty or whether it wants to incorporate the medical degree. In the USA where this trend initially started, the practice of the specialty is protected by national, regional, and local legislature as a dental specialty. In reality, there is no perceivable practical difference in the scope of practice between single- or double-degree practitioners in the States. In the UK and many parts of Europe, the specialty has taken leaps and bounds toward the medical path of training and it could very well be only a matter of time before the Specialty remains only remotely associated with Dentistry. The primary challenge was a lack of understanding, which centered on the debate of whether a medical as well as a dental qualification was required prior to surgical training [5].

Oral and maxillofacial surgery remains a specialty of dentistry in India and most training programs involve a graduate study and thesis to obtain the Masters in Dental Surgery (MDS) degree. The dental practice act allows all qualified dentally trained oral and maxillofacial surgeons to practice the unrestricted and full scope of the specialty, similar to what occurs in the European nations that require a medical degree. In most of Europe, OMS has become a medical subspecialty.

Public perception of the scope of practice of the specialty remains below par. The specialty gets confused with other surgical domains within both dentistry and medicine that we share a scope.

\subsection{Expertise, Familiarity, and Competence}

"Innovation is the combination of different ideas and contribution of the different minds."

Laskin [6] attempts to address this problem by dividing the scope of oral and maxillofacial surgery into three parts: areas of expertise, competence, and familiarity.

- Areas of expertise include oral pathology/oral medicine, dentoalveolar surgery, preprosthetic surgery (including implantology), and maxillofacial traumatology.

- Areas of competence involve orthognathic surgery, temporomandibular joint surgery, and local reconstructive surgery.

- Areas of familiarity are cleft lip and palate surgery, regional reconstructive surgery, oncologic surgery, craniofacial surgery, and cosmetic surgery.

Laskin's system of classification, while seemingly appearing comprehensive, opens itself to a lot of debate and question. While there is no doubt that the areas of "expertise" are unique to our specialty, it is our foray into those areas of competence and familiarity that has led to the expansion of the scope of our specialty. This expansion and contraction of our scope may also be fundamental to continual evolution. A large majority of our colleagues in India and worldwide operate within the boundaries of that scope of practice defined as "expertise." However, to turn areas of familiarity into competence and expertise will require that the training units and staff have the required skills and volume of cases to ensure hands-on experience and documentation. Only under these circumstances can we be assured that the skill sets and competencies will be transferred and become enduring.

It is ideal that all trainees are trained to achieve competence in craniomaxillofacial trauma, orthognathic surgery, and TMJ surgery (i.e., maxillofacial surgery). This and only this can provide the transition from Oral to Maxillofacial surgery. There, however, is a clear and present reality that not all training programs are equipped to achieve this goal. Even though training standards and syllabi exist, these standards are so broad that even programs with a very limited scope of training will meet accreditation standards by reporting a narrow set of hospital-based procedures that are not representative of the scope of practice required of modern OMS. Further, the interest of the trainee in training in the full scope of surgery is a factor that leads to mediocre training. The system of choosing a postgraduate training in OMS in India is severely handicapped and primitive. The factors that decide a trainee's choice of an advanced training program have nothing to do with their aptitude or interest in a specialty. It is purely based on their standing in a national entrance examination or their affordability of a position in a private institution. This leads to complete neglect of the student's natural aptitudes leading to prosthodontists becoming orthodontists and endodontists doomed into the world of oral and maxillofacial surgery. A disinterested trainee will be barely motivated to improve the scope of their practice following completion of their training, often limiting their practice to general dentistry and minimal indulgence in areas of "expertise."

Bell [7], when contemplating the future of education and training in the specialty, raises some very valid concerns, which seem to reflect the issues that affect the specialty and its future worldwide. Many reasons for the training disparities exist today-including training program location, the presence or absence of a trauma center, limited head and neck surgery experience, and local politics-but regardless, the goal should be the same: to train oral and maxillofacial surgeons to competence in the core areas of the specialty that they will eventually practice.

The key point is that we, as a specialty, should ensure that we train to competence and expertise based on geographic location, years in practice, fellowship training, and academic involvement. In years past, if an OMS graduate wished to obtain training in any areas beyond basics, then he or she often sought it outside of the specialty, in either oto- 
laryngology or plastic surgery. With the emergence of several teaching hospitals and colleges as well as standalone independent centers of excellence, this scenario has drastically transformed in India. Further, the development of a number of fellowships that have been facilitated by the AOMSI has resulted in a robust system within the specialty that caters to the trainee's desire, merit, and quite often desire to embrace technique and technology. The rapid and natural advent of OMS into areas of oncology and reconstruction, cleft lip and palate, craniofacial surgery, and aesthetic surgery has been unprecedented and the critical mass of those who now fit in comfortably with these are their areas of expertise is on the rise.

This has been a radical transformation. A few decades ago, wandering beyond the realms of dentoalveolar surgery and facial trauma inevitably encountered a glass ceiling. Today this has been most certainly breached. Moreover, while the majority of the specialty holds itself within the original areas of expertise, there is no doubt that the Big Bang Moment for OMS in India has happened and it is a great time to contemplate where we are heading. What does the future hold for the specialty as we drift on our very own Starship Enterprise?

\subsection{Predicting the Future}

"Look back over the past, with its changing empires that rose and fell, and you can foresee the future, too." Marcus Aurelius.

Are we truly at a threshold or are we pieces in some continuum? What factors will drive our evolution as a specialty in India and our extended regions? What trends can we predictably follow to predict our future? Can we perhaps take a page from other fields in medicine to learn about ourselves? Will changing attitudes and aptitude of a new generation have a powerful impact on our profession or will we forever remain loyal to the vestiges of the legacy left behind for us?

Technology will undoubtedly play an important role in our future. Not just technology in patient care, but technology in our lives. Telemedicine and teleconsults will become a part of our everyday practice allowing us to practice beyond geographic limitations. Teleconferencing will make biannual AOMSI face-to-face conferences obsolete. In 2018, the American Association of Oral and Maxillofacial Surgeons (AAOMS) simulcasted their Dental Implant Conference, as did the American Society of Anesthesiologists. Their experience is that the while their total registration at these meetings went up, the number of in-person registrants did not dissipate. Consultant oral and maxillofacial surgeons all over the world have embraced telemedicine naturally, whether they realized it or not. Mobile technology allows the transfer of patient images and radiographs easily both for opinions and treatment planning. Such ease of access to patient images and documents has become a routine tool in emergency room triages of patients in the evaluation of the priority of care.

While technology in its current form is often perceived, as interruptive to one's lifestyle choices, the advent and immersion of artificial intelligence (AI) will make today's technology ubiquitous without being intrusive. Operating theaters of the future are likely to be guarded by artificial intelligence. Imagine an operating theater that prepares itself based on the radiofrequency identification (RFID) of the surgeon who swipes her/his badge at the door-that surgeon's preference cards get read by the system and a central core will prepare the instruments and supplies based on that surgeon's choices for that particular case booked for him.

Anesthesiology, radiology, and pathology are lowhanging fruits in the AI world. Radiologists in large tertiarycare centers in China, today, do not read radiographs anymore; they simply look at false positives read the previous night by their AI system. The system then learns from such mistakes and makes corrections forever. Computer systems today have the capacity of a thousand human brains to process data. The more data we feed these AI systems, the smarter they get. Google's AI product called LYNA or LymphNode Assistant is a trained algorithm that is capable of spotting the features of tumors that have metastasized, which are notoriously difficult to detect. Self-teaching algorithm systems will likely replace monitoring duties of the anesthesiologists and critical care nurses in the hospital.

Surgical robots are also constantly evolving incorporating precision haptics and AI. Robotic arms can already perform tasks independent of a surgeon yielding it. Imperfections and errors that a surgeon may cause in an operation are avoided in robotic surgery by consistent movements, angles, and access that can only be achieved by that robot. Imagine a robotic arm that can be programed to remove a mesioangular impacted mandibular third molar? The robot surgeon can assess the angulation of the impacted tooth based on the patient's radiograph, adjust its angulation and access, make a buccal trough, and split the tooth precisely. Less error and more precision, perhaps?

The day is not far before a robotic arm can obtain a tissue sample from our patients at a mall kiosk. Algorithms can then diagnose that tissue and their radiographs distancing the patient further away from the conventional practice of medicine. What is the future of our practices and our education in these scenarios? A well-informed patient with access to information and technology may surpass the traditional medicine man for their healthcare. Direct to consumer marketing of healthcare tools such as genetic testing is already prevalent in many countries. Several patients are aware of which chemotherapy may be best effective for the management of 
their cancers even before they see their doctor, today. Where does that place a specialist in the future?

In a keynote address at the Royal College of Surgeons in London at the 50th anniversary of the IAOMS, Brian Schmidt DDS, MD, PhD, Director, Bluestone Center for Clinical Research, and Professor of Oral and Maxillofacial Surgery at New York University pondered about the future of OMS internationally. He emphasized three units of care that oral and maxillofacial surgeons provide universally-

1. Management of maxillofacial trauma.

2. Management of oral cancer.

3. Management of craniofacial anomalies.

His views suggested that the advent of seatbelts, airbags, and safer road conditions in most countries is diminishing our total volume of trauma. Further, patterns of wars have changed from the bayonets of World War I to dronecontrolled annihilation that ensures death! While bar fights and interpersonal violence continue to create left-sided ZMC and mandibular fractures, the world of facial trauma is most certainly changing.

He recognized examples of how personalized medicine is influencing the care of cancer patients. With our ability to map genomes and mutations, our ability to interpret cancer biology has had a meteoric rise even in the last decade. This leads to personalizing management via either chemotherapy or radiotherapy with predictable success making most cancers chronically manageable diseases rather than a death sentence. The future of personalized medicine will most likely put the cancer surgeon out of an occupation.

He introduced a study that demonstrated how a serendipitous finding in mice with Treacher-Collin's syndrome treated for endometrial cancer with a chemotherapeutic agent knocked out the gene causing the craniofacial anomaly in the following generation. This suggested that we could potentially be looking at gene therapy for craniofacial anomalies, including cleft lip and palate.

Schmidt's observations and predictions suggest that the diseases and conditions that are the mainstay to our profession will alter significantly in the future. Laboratories in Boston are very close to creating a template stem cells construct that will replace dental implants with naturally grown teeth. A dental caries vaccine is pending worldwide use.

How will these fundamental changes alter the practice of our specialty in the future?

Super specialization within the specialty is bound to happen. Attendees of the annual sessions of the British Association of Oral and Maxillofacial Surgeons will be struck by the design of the sessions. There are sessions designed for oral surgeons, implantologists, educators, deformities surgeons, ablative surgeons, and separately for reconstructive surgeons, as there are for minimally invasive surgery, aesthetic surgeons, and lab research. Larger sister specialties like ENT-Otolaryngology have also separated themselves into subspecialties. In the US, Pediatric otolaryngology, head and neck Surgery, facial plastic surgery, otology, skull-based surgery and surgery for sleep disorders are all recognized subspecialties within ENT in the US, for which fellowship training is offered. The pediatric otolaryngologist who specializes in airway surgery is unlikely to attend a conference organized for the otologists.

Similarly, domains within oral and maxillofacial surgery are already starting to branch out into subspecialty pods and practices are being limited to the practice of such subspecialties. That focus on a specific area within the specialty is also likely to be influenced by reimbursement for services. The subspecialties that rake in more money for the provider will thrive quicker and heftier than the latter. Changes in reimbursement strategies by hospitals will also evolve in this equation. For instance, in the US, where a large third-party payer system exists, clinical production for a practitioner is often not measured in actual dollars, but in revenue value units (RVUs). Complex longer cases like a head and neck disease ablation and reconstruction may not be related to a large reimbursement of dollars for the surgery alone; but the fact that the operating facility was used for several hours with the utilization of other resources such as nursing care, critical care, specialists like physical therapists, speech therapists, nutritionists, and a follow-up rehabilitation facility, all add up value to the health system ensuring reimbursement.

While this model seems to be working for now, the practice of medicine in the future unfortunately will be largely devised by the market and economics. The educational debt for training our future generation is getting out of hand. In a world where access to information is undoubtedly easier, the cost of a formal education is skyrocketing. Alternate models of education may arise disrupting this traditional model. Apprenticeships of the Osler era may be aft. Centers of excellence are likely to develop that allows a pathway of nontraditional training to an interested and talented trainee. Validation agencies like the International Board of Certification of Oral and Maxillofacial Surgeons (IBSCOMS) will have a bigger role in providing bonafide certification outside of the current commercialized and often-diluted education system.

The millennial and the gen $\mathrm{Z}$ student will also play a large role in the evolution of the specialty. Today's trainee learns differently, synthesizes information differently. They grew up on smartphones and Google searches and not in libraries or poring over Encyclopedia Britannica. They are visual learners with a panache for hand-eye coordination. They are multitaskers. No doubt that there will exist friction between a generation of older teachers and this generation of learners. And, that too will only be momentary. The new trainee is 
focused on lifestyle choices and is not unabatingly focused on education and patient care. The new trainee values life outside of work just as much as work. This will bring a new kind of diversity to the workplace. To make things worse, they will be treating a generation of aging patients who are used to a different kind of doctor from their times. The average patient is older and healthier and has demands that may have been considered unreasonable at one time. They are likely to be tech-savvy themselves. They will seek many opinions before they commit to the recommendations of their provider. They are likely to choose a surgeon based on the reviews on social media and the internet. Globalization of the medical industry and technology means that they might be willing to travel to have the same procedure and product used elsewhere than their hometown hospital.

Surgeons are working longer than they ever did as well. What impact does that have in a crowded marketplace? Will aging populations of patients and surgeons see an impact on the way we work? Will longevity and increased career years keep the younger ambitious surgeon from getting to the top? The retirement age of surgeons differs all over the world. Surgery is mentally and physically demanding. What effects does that chronic stress have on both the cognitive and physical decline in surgeons? Bhatt et al. did a narrative review on the topics of "ageing" and "surgeon" in Medline in 2016 [8]. They could not find any common ground in these studies. A surgeon who has to hang up his knife at 40 because of severe carpal tunnel in his hands is very different from one that has excellent physical health but severe cognitive decline. The variables were too many for them to consider any consensus on their research question- "when should surgeons retire?" They concluded that," Competence should be assessed at an individual level, focusing on functional ability over chronological age; this should inform retirement policies for surgeons."
OMS is like no other branch of medicine or dentistry. It has innovated, expanded, and usurped. It has replicated the old kingdoms, which created vast expanses as it rolled along. Eventually though, experience tells us that it can collapse under its own weight and might. As we look into the future, we must not ignore our past. Empires end for two reasons... problems from within and failure to protect their borders. As for empires, so for OMS. Our mistakes and pettiness must be acknowledged, accounted for, and learned so as not to repeat them.

We might have the ability as a specialty to control most of our destiny, but some of it may be adapted based on our environments. At the end of it all, if the specialty takes heed of three fundamental principles-patient care, education, and meaningful research, we will continue to justify our existence in the future.

\section{References}

1. Suśruta Samhita. English translation by Kaviraj Kunja Lal Bhishagratna, Calcutta, 1907, Chapter 16, 152-154.

2. Raju VK. Suśruta of ancient India. Indian J Ophthalmol. 2003;51:119-22.

3. Paul G. The future of maxillofacial surgery as a specialty of dentistry. J Maxillofac Oral Surg. 2017;16(1):1-2. Published online 2017 Jan 16.

4. Revised 2007 regulation of the Dental Council of India, Gazette of India Extraordinary No DE 22-2007, Government of India, dated 20th November 2007, pp 56-68.

5. Nayak K. Oral and maxillofacial surgery: It's future as a specialty. J Maxillofac Oral Surg. 2011;10(4):281-2.

6. Laskin M. The past, present, and future of oral and maxillofacial surgery. J Oral Maxillofac Surg. 2008;66:1037-40.

7. Bryan Bell R. Infinite cornucopia: the future of education and training in oral and maxillofacial surgery. Oral Surg Oral Med Oral Pathol Oral Radiol. 2016;121(5):447-9.

8. Bhatt NR, Morris M, O'Neil A, Gillis A, Ridgway PF. When should surgeons retire? Br J Surg. 2016;103(1):35-42.

Open Access This chapter is licensed under the terms of the Creative Commons Attribution 4.0 International License (http://creativecommons. org/licenses/by/4.0/), which permits use, sharing, adaptation, distribution and reproduction in any medium or format, as long as you give appropriate credit to the original author(s) and the source, provide a link to the Creative Commons license and indicate if changes were made.

The images or other third party material in this chapter are included in the chapter's Creative Commons license, unless indicated otherwise in a credit line to the material. If material is not included in the chapter's Creative Commons license and your intended use is not permitted by statutory regulation or exceeds the permitted use, you will need to obtain permission directly from the copyright holder. 